\title{
LOS EQUIPOS DE CONTROL Y VIGILANCIA AMBIENTAL. UNA ETAPA MÁS EN LA PROTECCIÓN DEL MEDIO NATURAL
}

\author{
(ENVIRONMENTAL CONTROL TEAMS, AN ADVANCE STAGE ON THE \\ ENVIRONMENTAL PROTECTION)
}

\author{
José Luis Canga Cabañes, Raúl Bueno Hernández y \\ Encarnación Martínez-Aedo Ollero \\ INYPSA \\ Informes y Proyectos, S.A
}

Fecha de recepción: 27 - IV - 93

ESPAÑA

$113-17$

\section{RESUMEN}

Comienza a admitirse de forma general que las consideraciones medioambientales deben intervenir como un elemento más en todas las fases de definición de los proyectos de infraestructuras $y$ obras civiles, con distintos niveles de intensidad segin las etapas: desde las más generales, en que el concepto que se maneja es la ordenación del territorio; pasando por otras más avanzadas en que se habla ya de Evaluación de Impacto Ambiental; hasta las más detalladas en que se definen a nivel de Proyecto las medidas correctoras $y$ de revegetación.

En este momento parece clara la necesidad de progresar un paso más y generalizar la presencia a pie de obra, en grandes obras de infraestructura, de Equipos de Control y Vigilancia Ambiental que supervisen la adecuada aplicación de las medidas correctoras de impacto $y$ de revegetación.

\section{SUMMARY}

It is felt in a general way that environmental considerations must be part of all stages when defining proyects of infraestructure and public works, with different degrees of intensity depending on which stage: first, we deal with the regional planning; in a more advanced stage the environmental impact assessment takes place; and finally, a plan of corrective and revegetation mesures is prepared.

Now, it would be necessary to generalize the presence of environmental controlling vigilant teams to supervise the correct application of the corrective and revegetation mesures during the construction of big public works.

\section{INTRODUCCIÓN}

La realización en España de los estudios de efectos ambientales causados por la realización de infraestructuras y distintas obras públicas se remonta a la década de los años 70. En ellos se consideraban los factores ambientales afectados y se establecían recomendaciones generales para minimizar las alteraciones detectadas.

Posteriormente, con el R.D. Legislativo 1302/86 de 28 de junio de Evaluación de Impacto Ambiental (EIA) y su correspondiente Reglamento de ejecución aprobado en el R.D. 1131/88 de 30 de septiembre se establece definitivamente el marco legal en el que se encuadran estos estudios.

Desde entonces, y como consecuencia de la experiencia adquirida al llevar a la práctica la realización de EIA, se han suscitado numerosas opiniones e interpretaciones sobre los diferentes proyectos que deberían ser sometidos a este proceso; tas distintas fases del proyecto en que han de aplicarse; los contenidos mínimos que deben contemplar; los métodos de elaboración más adecuados, etc. 
Asimismo, en numerosas ocasiones se han reflejado las deficiencias y carencias de dichos estudios, cuestionándose incluso su utilidad y viabilidad práctica.

En este sentido, el presente artículo pretende constituir una aportación de soluciones que garanticen la efectividad de los estudios de impacto ambiental, poniendo de manifiesto los importantes beneficios (ecológicos, sociales, económicos y paisajísticos) que pueden generarse de la oportuna aplicación de sus medidas correctoras.

El análisis que a continuación se expone hace referencia a proyectos de infraestructuras lineales (autovías, autopistas, vías férreas, canalizaciones, gasoductos, oleoductos, etc). Se describe la aplicabilidad de medidas correctoras durante el proyecto, y se pone de manifiesto la necesidad de un equipo de especialistas a pie de obra, que supervise la puesta en práctica de dichas medidas.

\section{1.- APLICABILIDAD DE MEDIDAS CORRECTORAS DE IMPACTO AMBIENTAL DURANTE EL PROYECTO}

Los estudios de EIA no sólo deben considerarse como instrumentos preventivos de afecciones negativas, sino que constituyen un elemento potenciador de impactos positivos a la vez que aportan al proyecto de la obra mejoras que disminuyen los riesgos de accidentes y facilitan el mantenimiento de la infraestructura.

La elaboración de cualquier proyecto conlleva la realización de distintos documentos que evolucionan progresivamente en la definición y desarrollo de las características del mismo. Así, y en líneas generales, se pueden distinguir 3 fases: Anteproyecto, Proyecto de trazado y Proyecto constructivo.

De igual manera, el estudio de impacto ambiental, y más concretamente la aplicación de medidas correctoras, deben evolucionar paralelamente a las fases descritas, de manera que se logre una interacción de soluciones entre ambos (Proyecto y EIA).

El estudio de impacto ambiental deberá, por tanto, iniciarse desde el primer nivel de planificación de la obra (Anteproyecto). Se determinará la viabilidad del proyecto, y se seleccionarán las áreas o pasillos con mayor capacidad de acogida garantizando que no se vea gravemente afectado el territorio.
Esta primera definición de "pasillos óptimos" constituye en sí una medida correctora, ya que en muchas ocasiones se evitan, a priori, posibles alteraciones que con posterioridad sería más costoso solucionar.

Al iniciarse el Proyecto de trazado, el EIA deberá continuar profundizando, conjuntamente al grado de definición del proyecto. En este caso, el análisis del medio físico y social afectado adquiere su mayor desarrollo, debiendo ser exhaustivo y detallado con el fin de posibilitar la optimización definitiva del trazado a seguir.

Paralelamente, se procederá a la valoración cuantitativa y cualitativa de los impactos detectados de manera que se puedan definir las medidas correctoras oportunas, que deberán ser desarrolladas e integradas a la hora de abordar el Proyecto constructivo. Así, se conseguirá minimizar en gran parte los impactos detectados.

Por otra parte, las modificaciones que con frecuencia se producen en el Proyecto constructivo con respecto al de trazado conllevan la necesidad de comprobar que no se generan nuevos impactos y caso de producirse establecer nuevas medidas correctoras. Es el momento de definir con precisión el Proyecto de Medidas Correctoras de Impacto Ambiental, en el que se incluirán las labores de revegetación oportunas.

Finalmente, debe redactarse un Plan de Vigilancia y Control que contemple la puesta en práctica de las medidas propuestas.

Todavía no ha calado suficientemente la idea de que el condicionado de las declaraciones de impacto ambiental, con los Proyectos de medidas correctoras y Programas de vigilancia que implican, son de obligado cumplimiento. En general las empresas constructoras demuestran una escasa predisposición al respecto, cuando no una actitud claramente negativa e incluso hostil, aunque justo es reconocerlo empiecen ya a existir precedentes esperanzadores. Si en condiciones normales se hace necesaria la presencia del Equipo de Control y Vigilancia Ambiental, aún lo es más en la situación actual de falta de mentalización general al respecto.

A continuación se desarrolla en breves trazos la posible labor del Equipo Ambiental, diferenciando dos etapas principales:

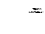

a) Supervisión de las medidas correctoras de impacto ambiental previas a la revegetación. 
b) Supervisión de las medidas de revegetación.

\section{SUPERVISIÓN DE LAS MEDIDAS CORRECTORAS DE IMPACTO AMBIENTAL PREVIAS A LA REVEGE- TACIÓN}

Habitualmente la aplicación de medidas correctoras de impacto en una obra lineal se reduce a las siembras y plantaciones realizadas en algunas de las superticies más visibles, después de finalizadas las obras. Este planteamiento de la recuperación ambiental desaprovecha la oportunidad que existe en la fase de construcción para evitar algunos impactos y reducir la magnitud de otros.

En la construcción de una infraestructura lineal el enfoque correcto para la aplicación de medidas correctoras es evitar la aparición del mayor número de impactos posibles en todas las actuaciones a desarrollar y desde el mismo momento en que aparecen los primeros grupos de personal y maquinaria. Es necesario tener presente que desde el punto de vista ambiental es menos perjudicial la no aparición del impacto que la posterior corrección, ya que incluso con la aplicación de una buena medida correctora es difícil reproducir las condiciones de partida, que en el caso menos complejo son el resultado de la interacción de numerosos factores ecológicos durante un largo período de tiempo. Económicamente es también más ventajosa la prevención de posibles impactos pues hace menos costosa la aplicación de medidas correctoras y mejora su eficacia.

Para conseguir que la construcción de la obra cause el mínimo impacto posible en el entorno receptor se impone la realización de un detallado proyecto de medidas correctoras que, lejos de las habituales recomendaciones generales que acompañan a los Estudios de Impacto Ambiental, se ajuste a las condiciones ambientales de cada zona y a las características técnicas de la infraestructura proyectada, detallando a nivel de proyecto las medidas correctoras a aplicar. Su puesta en práctica hace imprescindible la presencia a pie de obra de un Equipo de Control y Vigilancia Ambiental que compruebe la adecuada aplicación de todas las actuaciones previstas, supervise los trabajos realizados, asesore a la Dirección de Obra y mantenga una estrecha relación con los representantes del órgano ambiental competente, conservando siempre la capacidad de decisión ante imprevistos que necesiten una rápida actuación, hecho muy frecuente en la ejecución de una obra de este tipo. Evidentemente la presencia en obra del equipo técnico ambiental será permanente o intermitente dependiendo tanto de la magnitud de la obra como del coste total de la parte de medidas correctoras, de forma que pueda abarcar y solucionar fácilmente los problemas que aparezcan a lo largo de todo el trazado, a la vez que el coste de sus trabajos es asumido por los presupuestos iniciales.

La preparación e impartición de cursillos de formación ambiental al personal de obra puede ser una forma de conseguir pautas de actuación tendentes a reducir la incidencia de las actividades que desarrolla cada uno de ellos, desde los técnicos y personal especialista a la mano de obra no especializada. Sería muy conveniente que estos cursillos quedaran incluidos en todo proyecto de medidas correctoras, ajustándose su contenido y momento de impartición al personal al que va dirigido (ingenieros, maquinistas, encofradores, soldadores. inspectores, peones, etc.) y al tipo de obra (carreteras. gasoductos y oleoductos, líneas eléctricas, ferrocarriles, etc.)

A continuación se detallan algunos aspectos de las actuaciones básicas que con frecuencia se establecen en el proyecto de medidas correctoras y que el Equipo de Control y Vigilancia ha de desarrollar o supervisar durante la fase de construcción:

\section{Cursillo de formación del personal participante en las obras}

En nuestro país es una práctica aplicada en muy pocas ocasiones siendo por ello difícil extraer conclusiones sobre su efectividad, aunque se puede destacar una cierta reticencia del personal ante la proposición de una nueva conducta laboral. Ésta en muchas ocasiones es totalmente contraria a las actitudes y comportamientos habitualmente desarrollados en el trabajo diario, que generalmente son poco respetuosos con el medio natural

Es evidente que esta tarea requiere un largo período de tiempo para que se produzca el cambio de mentalidad necesario orientado hacia un total respeto al entorno por lo que es necesario plantearse su práctica desde el momento actual.

\section{Conservación de la tierra vegetal} $=$ $-$

Esta actuación se suele incluir dentro de las medidas correctoras que de forma general suelen acompañar 


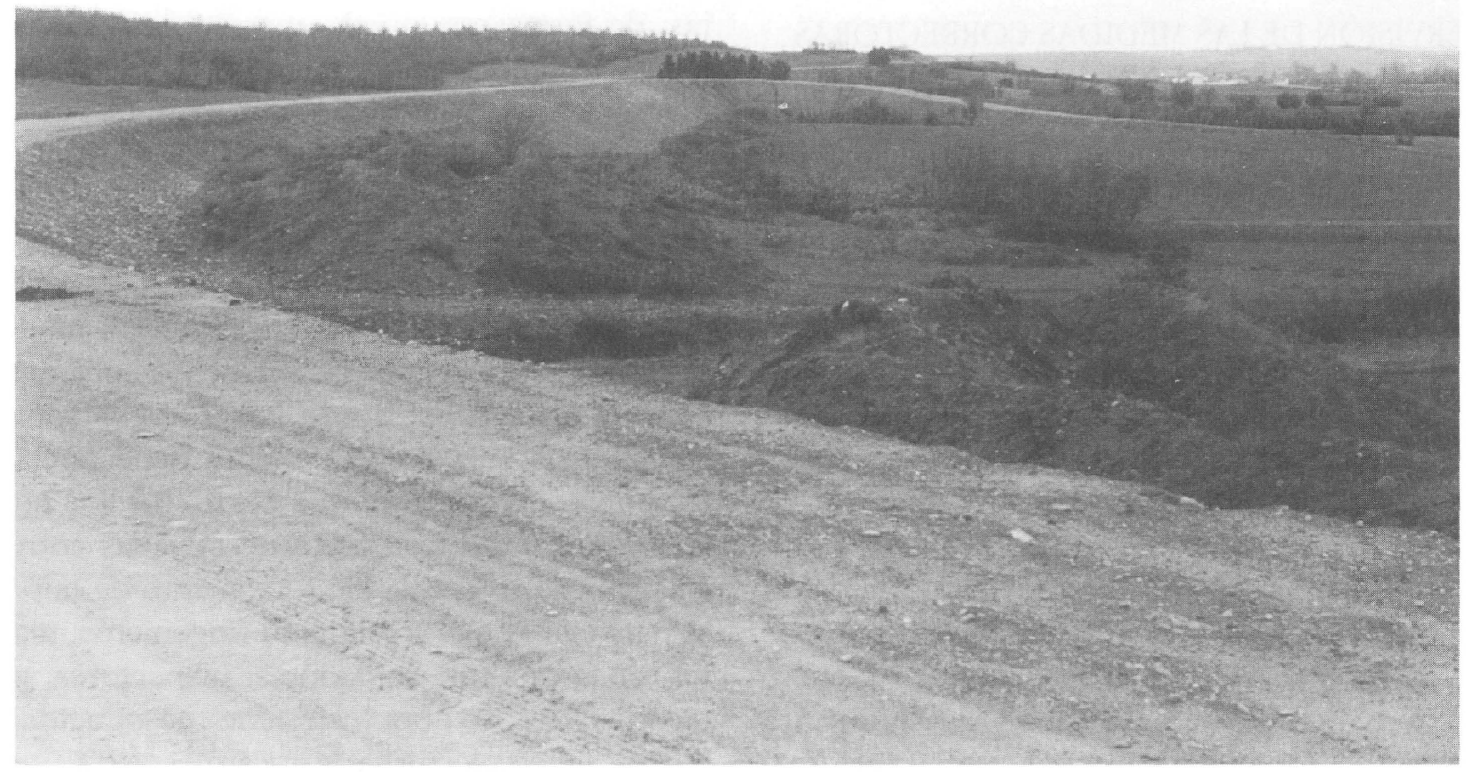

Foto 1.- En la foto puede apreciarse el acopio del cordón de tierra vegetal al pie del talud. La cubierta herbâcea que crece sobre él es indicativo de un buen estado de conservación y promesa de una buena marcha de la revegetación cuando se extienda sobre el terraplén.

a los Estudios de Impacto Ambiental, siendo poco frecuente en obra su correcto tratamiento y su posterior utilización, debido posiblemente al espacio que ocupan las tierras durante toda la fase de construcción y a que sólo se evalúa su coste económico, sin considerar el papel decisivo que con frecuencia juegan en el éxito de la revegetación y el ahorro que a la larga suelen comportar.

El espesor de la capa de tierra vegetal varía considerablemente de unos lugares a otros, siendo también variable la posibilidad de una extracción adecuada de la misma debido a la existencia de pedregosidad o pendiente. Siempre que sea posible se recogerá el suelo vegetal junto con la propia cubierta herbácea y subarbustiva de todas las superficies afectadas por la construcción de la obra. En el caso de infraestructuras viarias se retirará de aquellas superficies que posteriormente albergarán las calzadas, arcenes, mediana, vías de servicio y vertederos. Para las conducciones subterráneas (gasoductos, oleoductos, cables, etc.) se pondrá especial cuidado en no mezclar la tierra vegetal obtenida de la pista de trabajo con la tierra extraída de la zanja donde se enterrará la tubería, para lo que se formarán dos cordones diferentes a ambos lados de la pista de trabajo (Foto 1).

La tierra vegetal obtenida in situ constituye un soporte inmejorable para la recolonización vegetal de aquellas superficies que han quedado desprovistas de vegetación como consecuencia de las obras, debido a su contenido en semillas y microfauna simbiótica. Es importante realizar tanto una cuidadosa extracción como un cuidadoso almacenamiento y conservación durante todo el tiempo que dure la obra, exigiendo una ubicación adecuada en terreno lo más llano posible para evitar la pérdida de nutrientes o de la propia tierra (la ubicación puede ser a veces difícil en el caso de conducciones subterráneas que discurren por líneas de máxima pendiente), un apilamiento en acopios de escasa altura para evitar compactación de las capas inferiores, y en algunas ocasiones un tratamiento de siembra y abonado que reponga las pérdidas de materia orgánica y nutrientes minerales. 

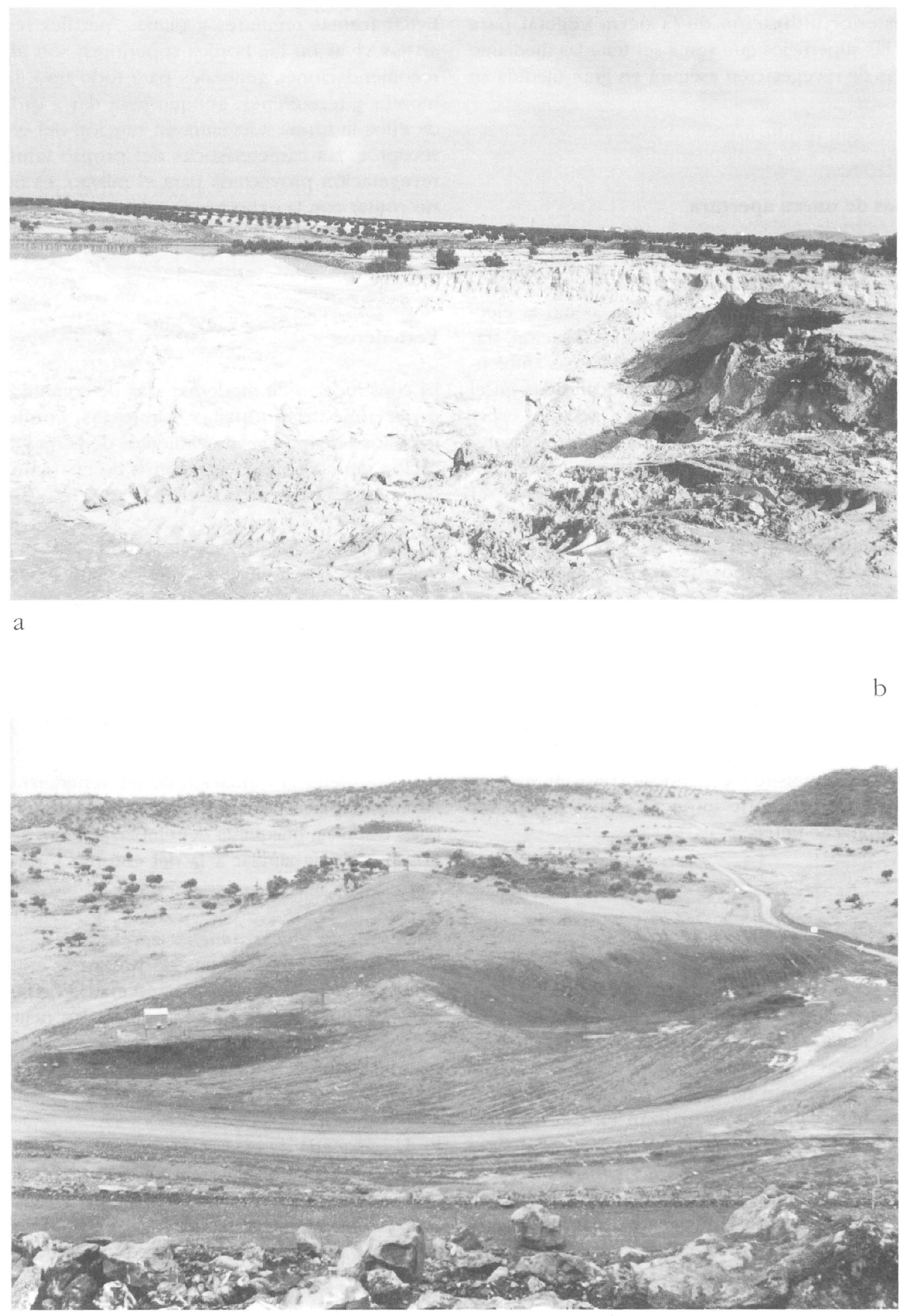

Fotos 2.- Las zonas de préstamo producen un impacto visual elevado debido a la cavidad originada y a los taludes con aristas angulosas y superficies planas (foto a). Una adecuada remodelación de estas zonas permite disimular en gran medida su ubicación (foto b). 
La posterior utilización de la tierra vegetal para cubrir las superficies que van a ser tratadas mediante técnicas de revegetación asegura en gran medida su éxito.

\section{Accesos de nueva apertura}

El proyecto de medidas correctoras ha de contemplar inexcusablemente tanto la restauración de todos los accesos abiertos durante la obra, como la elección de los lugares idóneos para su localización, trazado y forma de apertura, evitando las áreas ambientalmente sensibles que hayan sido localizadas en el Estudio de Impacto Ambiental. Este aspecto es especialmente importante en áreas naturales no humanizadas, zonas de montaña y laderas con fuertes desniveles donde la construcción de un acceso puede ser tan impactante como la infraestructura en construcción. La utilización de caminos y sendas rurales ensanchados y reparados ha de ser prevista como una alternativa útil de la apertura de nuevos accesos en la construcción de gasoductos y oleoductos, ya que a pesar de que habitualmente presentan un largo y tortuoso recorrido por las laderas permiten el paso de los vehículos todo terreno para transporte de personal que forman el grueso del tráfico de acceso a la pista de trabajo (la maquinaria se mueve a lo largo de la misma), evitándose construir accesos cortos pero con fuerte impacto visual y grandes movimientos de tierras.

\section{Taludes}

La aplicación de medidas correctoras sobre la forma de los taludes de terraplenes y desmontes es relativamente sencilla y económica en el mismo momento de su realización, debido a que sólo supone un pequeño incremento de tiempo respecto a los taludes que habitualmente se realizan en este tipo de obras.

La forma de desmontes y terraplenes es muy importante a la hora de conseguir una buena integración paisajística, favoreciéndose además la implantación de la cubierta vegetal, tanto de forma natural como artificial. Superficies planas sobre laderas redondeadas dan lugar a un fuerte impacto paisajístico imposible de eliminar incluso con la revegetación, mientras que un desmonte con formas redondeadas y adaptadas al entorno, aun sin cubierta vegetal, queda integrado en la morfología del paisaje circundante.
Evitar formas regulares y planas, perfiles rectos y aristas vivas en los bordes superiores, son algunas recomendaciones generales para todo tipo de desmontes y terraplenes, aunque para dar a cada uno de ellos la forma adecuada en función del entorno receptor, las características del propio talud y la revegetación proyectada para el mismo, es necesario contar con la experiencia de un técnico ambiental.

\section{Vertederos}

La construcción de modernas vías de comunicación, especialmente autopistas y autovías, conlleva la necesidad de grandes movimientos de tierra y la ubicación permanente en vertederos de una gran parte del volumen excavado.

La elección de los lugares de vertido se hace por lo general teniendo en cuenta únicamente el aspecto económico, buscándose por tanto zonas próximas a la excavación realizada que a la vez tengan fácil acceso para los camiones. Estos emplazamientos, unidos a las formas que habitualmente se da a los vertederos, crean problemas ambientales, destacando entre ellos el fuerte impacto visual (Fotos 2, a y b).

Para conseguir la formación de un vertedero con el mínimo impacto posible es necesario considerar tres fases distintas: búsqueda del emplazamiento adecuado, morfología similar a la del entorno y revegetación:

Búsqueda del emplazamiento adecuado. Las cavidades formadas en las zonas de préstamo utilizadas para la obra y las canteras abandonadas de la zona, son excelentes emplazamientos para los materiales de vertido, pudiéndose realizar de esta forma una recuperación de la morfología y vegetación originales.

En la búsqueda de otros lugares de vertido hay que considerar los usos asignados al suelo por el municipio, usos actuales, vegetación o cultivos existentes, red de drenaje superficial, posibles afecciones a zonas de recarga de acuíferos, puntos de interés geológico, botánico y faunístico así como alteraciones previsibles en el patrimonio cultural, yacimientos arqueológicos, etc (Fotos 3, a y b).

Finalmente es importante buscar zonas que no sean visibles desde carreteras, áreas habitadas, miradores, zonas deportivas o de recreo, etc. 


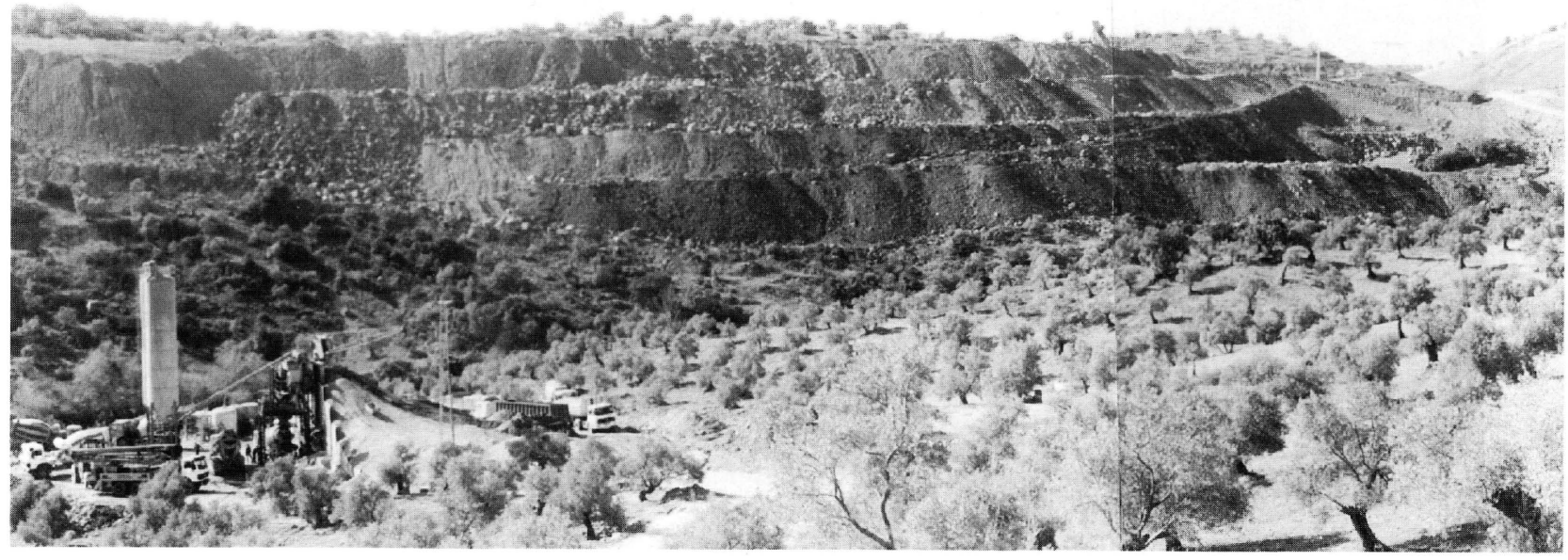

a

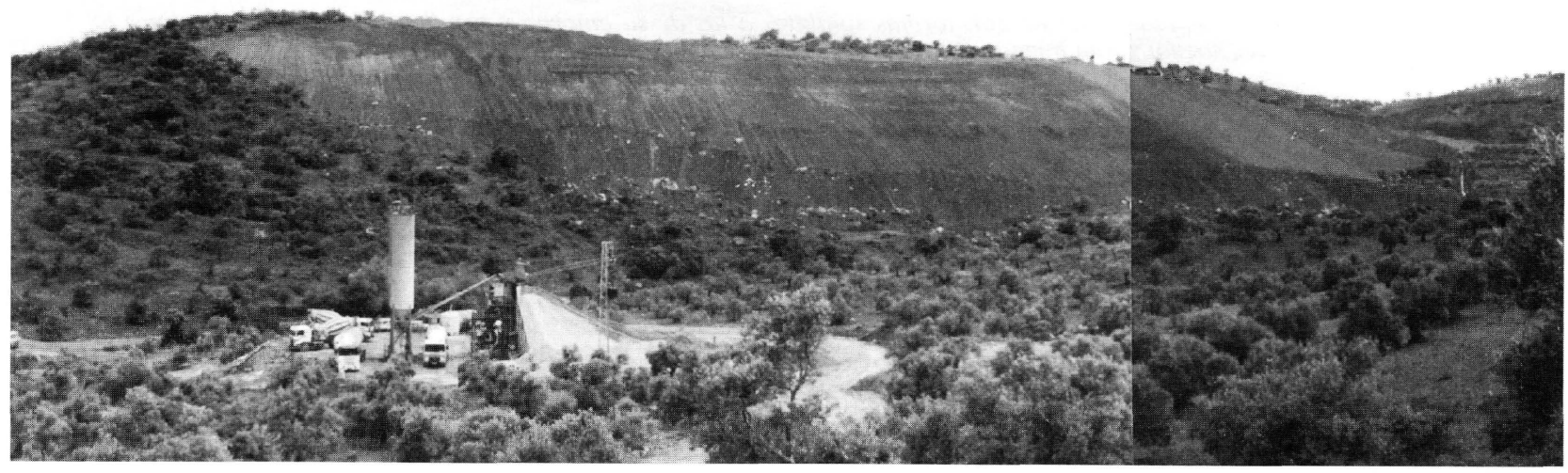

Fotos 3.- Las superficies planas y angulosas de los vertederos sin remodelar originan un fuerte impacto visual (foto a) que puede ser eliminado redondeando sus formas y adaptándolas a la morfología del terreno, con lo que se consigue una buena integración en el entorno (foto b)

Morfología del vertedero. Las formas del entorno receptor van a determinar la morfología del vertedero, que en todo momento ha de adaptarse a ellas. Por lo general las alturas bajas resultan menos perceptibles a la vista, siendo más conveniente realizar varios vertederos pequeños, alargados y bien integrados en el entorno, que uno de grandes dimensiones. En zonas suavemente alomadas se pueden crear montículos con formas redondeadas, que una vez cubiertos de vegetación serán muy similares a los naturales o rellenar pequeñas vaguadas o cavidades naturales elevando posteriormente el vertedero.

Revegetación del vertedero. Con las siembras y plantaciones realizadas en el vertedero y en sus proximidades se conseguirá disimular en gran medida su

(c) Consejo Superior de Investigaciones Científicas Licencia Creative Commons 3.0 España (by-nc) presencia, minimizada ya con la ubicación y morfología adecuadas.

\section{Impactos sobre la vegetación}

En los trabajos de explanación, apertura de pista, accesos, o cualquier actividad que suponga la eliminación de la cobertura vegetal, es importante la presencia del técnico ambiental con la finalidad de asegurar que no se afecta una superficie mayor de la que realmente se necesita. Esta labor se hace imprescindible en aquellas zonas de elevado valor botánico o paisajístico, así como en los cruces de los ríos, especialmente en aquellas infraestructuras en las que se necesita despejar de vegetación una amplia zona para que pueda trabajar la maquinaria. 


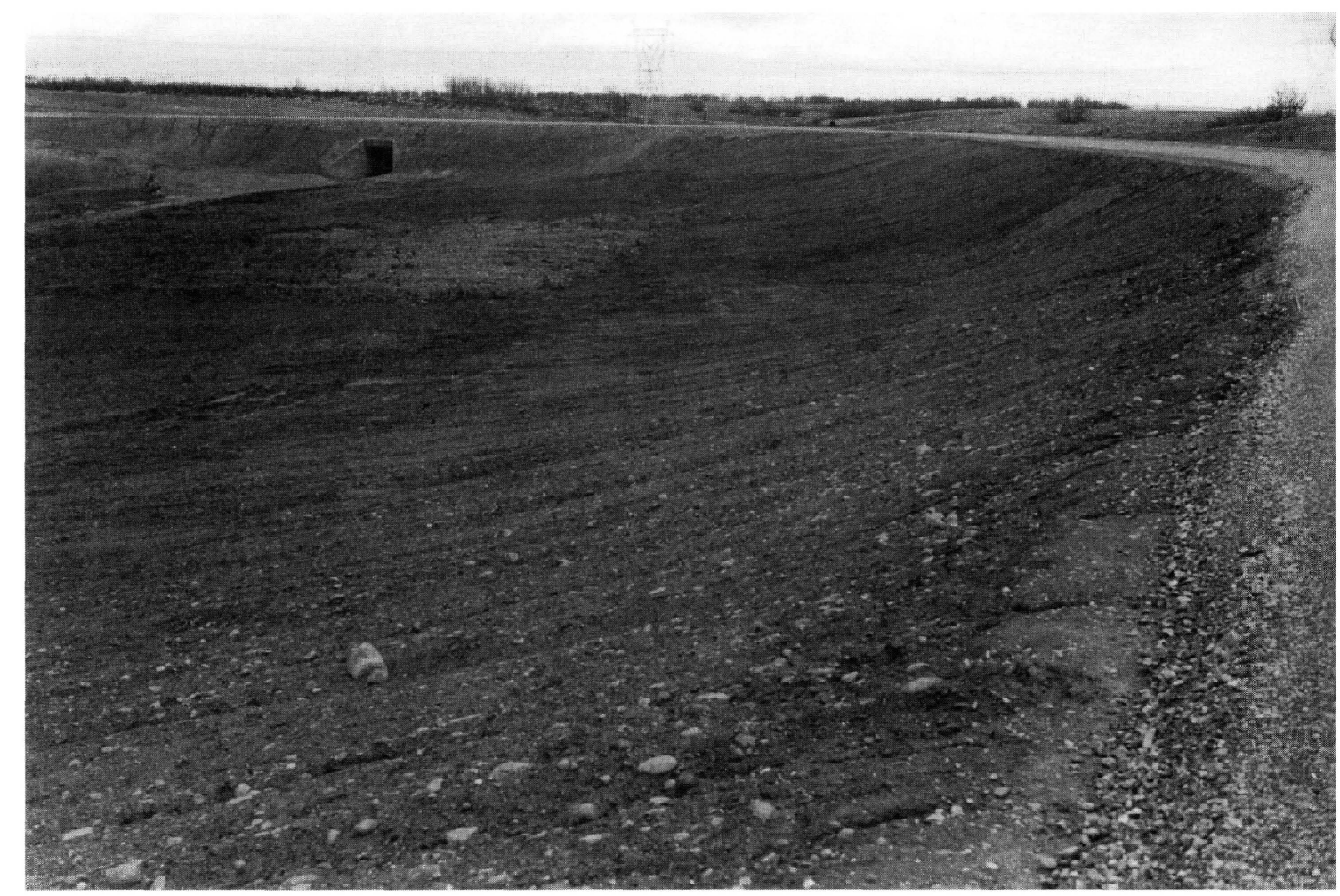

Foto 4.- Un buen remodelado del talud, con formas similares a las de su entorno y pendientes moderadas favorece la implantación de la vegetación y una buena integración paisajística.

\section{Impactos sobre la fauna}

La aplicación de medidas correctoras destinadas a reducir los impactos previstos sobre la fauna ha de comenzar en la fase de planificación de la obra, especialmente en aquellos casos en los que el Estudio de Impacto Ambiental haya detectado especies interesantes por su rareza, escasez o vulnerabilidad, de forma que se evite la realización de trabajos durante la época de reproducción en las áreas de cría previamente localizadas, tales como cortados rocosos, zonas encharcadas y riberas, bosques, etc. Las medidas a aplicar dependerán del tipo de obra y de las características de los ecosistemas atravesados, pudiéndose citar entre ellas:

- Restringir el uso de explosivos, utilizándolos únicamente en algunas zonas de la obra o en determinadas épocas. En algunos casos debe eliminarse su uso utilizando otros sistemas.

- Evitar o reducir al máximo la apertura de nuevos accesos a la obra.
- Si fuera necesario realizar las obras durante la época de cría, se realizarán recorridos de campo con antelación a la explanación o apertura de pista, por las zonas en las que sea probable la presencia de huevos o pollos de aves que aniden en el suelo o en árboles que vayan a ser derribados, pequeñas charcas de reproducción de anfibios, madrigueras de mamíferos, etc.

- Realización de recorridos de campo revisando las obras realizadas y comprobando su incidencia en especies terrestres. Este caso es especialmente importante en grandes canales de regadío abiertos, o gasoductos y oleoductos en los que la zanja permanece abierta largo tiempo, llegando a ser en determinadas ocasiones un obstáculo insalvable para algunas especies.

Los datos recogidos en las observaciones de campo pueden dar lugar a la adopción de medidas urgentes para evitar daños en esa temporada reproductora (cese inmediato del empleo de explosivos o tránsito de maquinaria pesada en las cercanías de nuevas localizaciones de nidos o colonias de cría, habilita- 


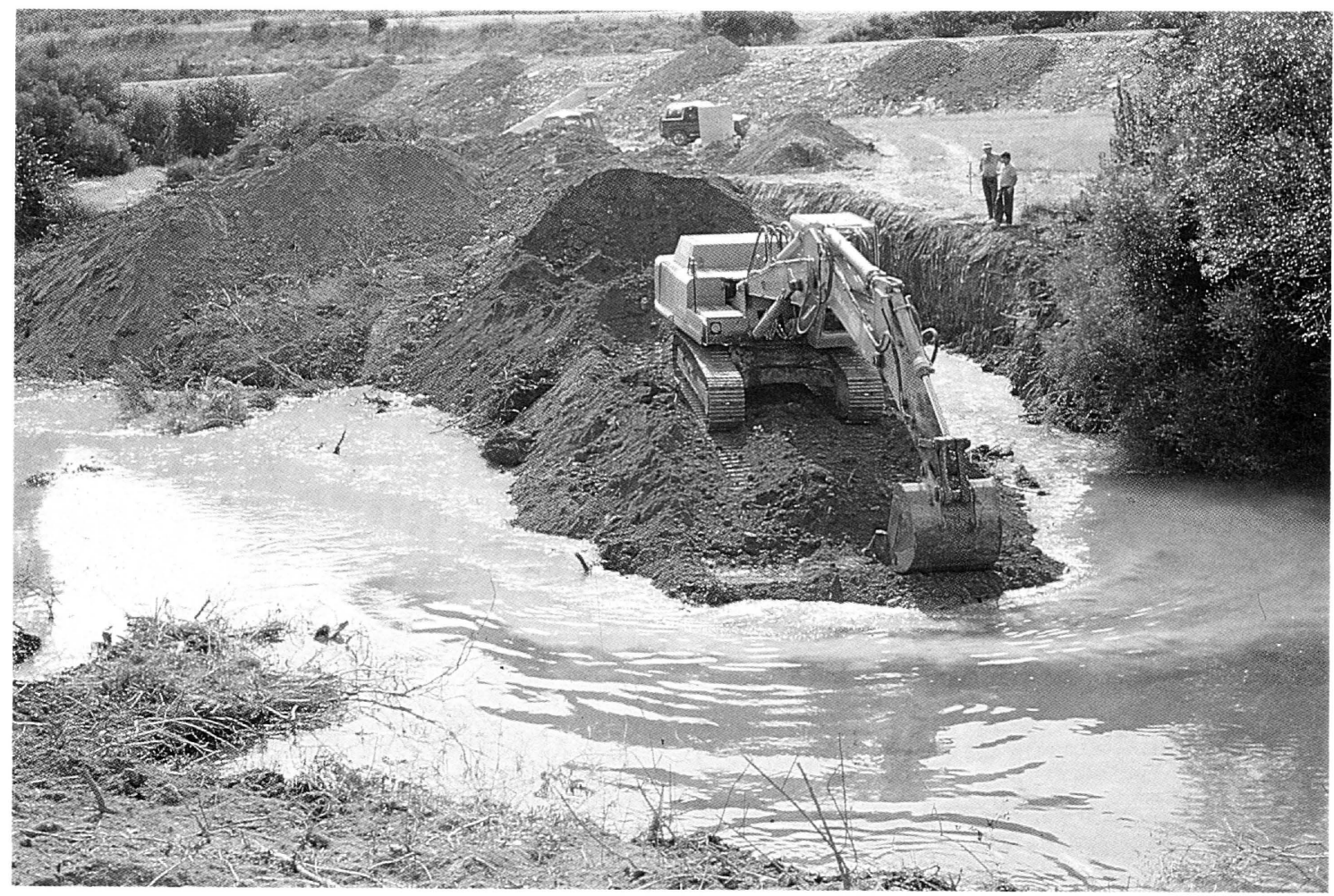

Foto 5.- La fiagilidad de los ecosistemas flutiales exige un control mut preciso de todas las actuaciones que se realicen en ellos, elaborando un preciso programa de medidas correctoras para reducir el impacto producido y lograr una recuperación de las características originales.

ción de zonas de paso para animales terrestres en el caso de zanjas, taludes. etc...) o la proposición de nuevas actuaciones no contempladas en el Proyecto de Medidas Correctoras (construcción de pasos de fauna o traslado de los proyectados a otros lugares que se han revelado como más idóneos,...).

La aplicación de todas las medidas correctoras comentadas, y que deben haber sido proyectadas con el detalle adecuado, exige la presencia a pie de obra del Equipo de Control y Vigilancia Ambiental. En efecto, es público que durante su ejecución los proyectos de obras de infraestructuras se someten a cambios significativos y que algunos aspectos causantes de fuertes impactos ambientales (vertederos, canteras, nuevos accesos, etc) con frecuencia se encuentran indeterminados o han de sufrir adaptaciones a la realidad de la obra. La inexperiencia de las empresas constructoras en estas cuestiones y la necesidad de hacer prevalecer el principio de prevención, que a la larga siempre es más barato, sobre el de corrección de los destrozos ocasionados, aconseja disponer sobre el terreno un Equipo de Control y Vigilancia Ambiental que supervise la aplicación de las medidas correctoras y resuelva en cada momento todas las circunstancias que vayan apareciendo (foto 5).

\section{3.- SUPERVISIÓN DE LAS MEDIDAS DE REVEGETACION}

El paso siguiente es la revegetación de las zonas afectadas por las obras. La labor del Equipo de Control y Vigilancia Ambiental puede resumirse en las siguientes fases:

\section{1- Contraste del Proyecto de Revegetación}

El primer paso es la revisión de los datos reflejados en el Proyecto de Revegetación y su contraste con el estado real de la obra. El caso más frecuente es aquel en que el Proyecto Constructivo de la Obra Civil sufre modificaciones en su ejecución. En ocasiones éstas son relevantes, como por ejemplo, un túnel que se transforma en una profunda trinchera o un viaducto que se sustituye por un terraplén. En ocasiones las modificaciones son menos importantes, desde el punto de vista constructivo, pero sí implican cambios significativos de cara a la revegetación: un terraplén más tendido se sustituye per un pedraplén, o la pendiente de los taludes resutta superior a la prevista, entre otras. Finalmente, la ejecución depara sorpresas que de ninguna forma podían pre- 

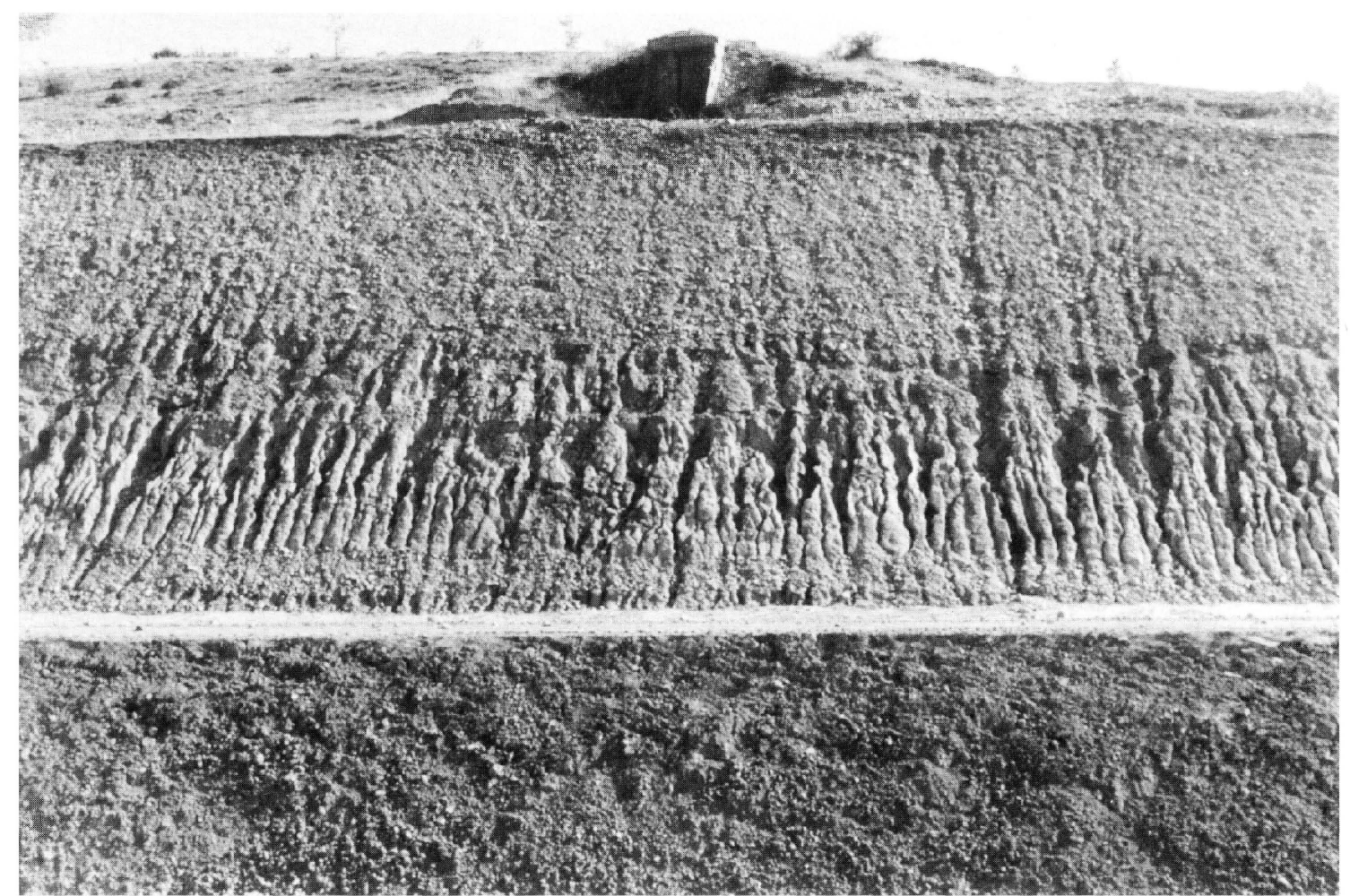

Foto 6.- Es preciso que las medidas de corrección de impactos ambientales se aborden cuanto antes, evitando la compactación superficial y el inicio de procesos erosivos en los taludes, lo que incrementa las dificultades de revegetación y eleva sus costes, al obligar a realizar trabajos preparatorios complementarios.

verse en el Proyecto: un desmonte corta una corriente subterránea de agua que fluye creando unas condiciones especiales de tratamiento; el acondicionamiento de un cauce natural que no se preveía modificar por su escasa importancia, obliga a un movimiento de tierras de cierta magnitud, creando una nueva unidad de actuación; la disponibilidad de materiales y las distancias de transporte obligan a dejar terraplenes con superficies más pedregosas de lo deseado, haciendo necesaria la adopción de nuevas soluciones pues las previstas resultan inaplicables; la abundancia de ganado incontrolado compromete seriamente los resultados. Finalmente, las limitaciones presupuestarias obligan a seleccionar las zonas de actuación prioritaria y a desechar la ejecución de labores en otras secundarias, decisión que necesariamente ha de contrastarse con la realidad de la obra.

Es también el momento de estudiar las variantes al Proyecto de Revegetación propuestas por el Contratista, analizando las ventajas e inconvenientes de las soluciones planteadas y su idoneidad para los fines deseados. Puede ser preciso definir nuevos precios.

En este punto resulta esencial la labor del Equipo de Control y Vigilancia Ambiental, que debe conducir a una definición clara y precisa del Proyecto de Ejecución, proponiendo soluciones a los nuevos problemas planteados y asesorando a la Dirección de Obra en la valoración de las propuestas del Contratista y en la toma de decisión final, así como en la fijación de los precios contradictorios que pudieran generarse

\section{2 -Programación de la revegetación}

A partir de los datos climatológicos medios y de la programación de la obra elaborados en el Proyecto de Revegetación, de su confrontación con las observaciones meteorológicas y tomando en consideración los usos y costumbres de la zona en estas labores, se deben fijar las épocas adecuadas para la ejecución de siembras, hidrosiembras y plantaciones.

Se procede también a supervisar que la programación efectuada por el Contratista y los equipos materiales y personales por él dispuestos permiten la ejecución de la obra en los plazos establecidos. teniendo en cuenta las dificultades de acceso, aprovisionamiento de agua y materiales, etc. existentes.

Conviene mencionar aquí que, en función del volumen de obra a ejecutar y de la complejidad de las 
soluciones adoptadas, puede hacerse necesario extender el período de ejecución a dos períodos vegetativos, con objeto de que al realizar la revegetación en dos etapas se aseguren mejor los resultados a obtener

La labor del Equipo de Control y Vigilancia, contrastando la Programación del Proyecto con la realidad y con la propuesta realizada por el Contratista se revela como una tarea básica en su labor de asesoramiento de la Dirección de Obra, pues de una adecuada elección de los plazos de ejecución depende en gran medida el éxito de la revegetación.

Esta programación debe coordinarse adecuadamente con la marcha de la obra civil, de manera que la revegetación sea lo más inmediata posible a la finalización de la primera y al mismo tiempo se evite que el paso de maquinaria o la realización de tareas constructivas cause daños evitables a las zonas ya restauradas. En este punto se hace preciso reivindicar el respeto de los equipos implicados en las labores propias de la obra civil al trabajo ejecutado en la revegetación, ya que por tratarse de unas labores erróneamente infravaloradas, con frecuencia sufren daños apreciables. No es raro observar árboles rotos, tumbados, descalzados, dañados, etc. por el paso de maquinaria, ...; tutores desaparecidos empleados en otros menesteres; zonas sembradas o hidrosiembras removidas o reperfiladas, en un admirable ejercicio de imprevisión y/o falta de respeto por la labor ajena. En este sentido, los cursos de formación de los equipos intervinientes en las obras cumplen una función esencial de mentalización, orientados a hacer comprender el significado, los objetivos y los beneficios de la revegetación, de manera que la negligencia haya de ser necesariamente culposa. En otro orden de cosas puede ser ejemplarizante la determinación de responsabilidades en los daños producidos y la obligatoriedad de abonar los gastos derivados de su reposición, incluso la imposición de sanciones en casos reiterados y fácilmente evitables. En esta labor, la función del Equipo de Control y Vigilancia Ambiental se muestra esencial como elemento imparcial entre los contratistas implicados (Foto 6).

\section{3.- Replanteo de la revegetación}

En esta fase se delimitan con precisión las zonas de actuación sobre las que se ha de trabajar, realizando el marqueo de las plantaciones y de las áreas a sembrar e hidrosembrar, de los emplazamientos de materiales especiales (mantas orgánicas, mallas plásticas, etc.), y en general de todas las operaciones a realizar en cada unidad de actuación de la obra.
Este trabajo permite:

a) Evitar la aplicación de técnicas de revegetación en lugares con escasas o nulas posibilidades de éxito: zonas rocosas o con una pedregosidad elevada; taludes con una pendiente excesiva o unos materiales de condiciones edafológicas especialmente desfavorables para la implantación de la vegetación, etc.

b) Decidir la técnica e intensidad de aplicación de las labores preparatorias de la revegetación (subsolados, escarificados, etc.).

c) Evaluar la necesidad de proceder a un mayor control de la escorrentía superficial y la solución más apropiada para conseguirlo.

d) Detectar enclaves de especial interés para la población cercana a la obra y que merecen un tratamiento diferenciado.

e) etc.

El recorrido detallado de la obra permite detectar y resolver las innumerables peculiaridades que cada obra presenta. Los criterios técnicos aportados por el Equipo de Control y Vigilancia a la Dirección de Obra permite atemperar los lógicos intereses del Contratista (elección preferente de aquellos trabajos con un mayor margen de beneficio y menos dificultades de ejecución) y definir las soluciones óptimas para el éxito de los trabajos de revegetación.

\section{4.- Control de los trabajos previos a la revege- tación}

En esta fase el Equipo de Control y Vigilancia comprueba el cumplimiento exacto de las especificaciones de los materiales establecidas en el Pliego de Prescripciones Técnicas y que las condiciones de acopio y almacenamiento de los mismos son las en él fijadas. A título orientativo se indican a continuación algunos materiales genéricos a los que resulta aplicable:

- Calidad y cantidad de las tierras vegetales y suelos aceptables, mediante muestreo aleatorio y los análisis correspondientes.

- Abonos y estiércol: muestras y análisis.

- Semillas: procedencia, especie, pureza, nascencia. 


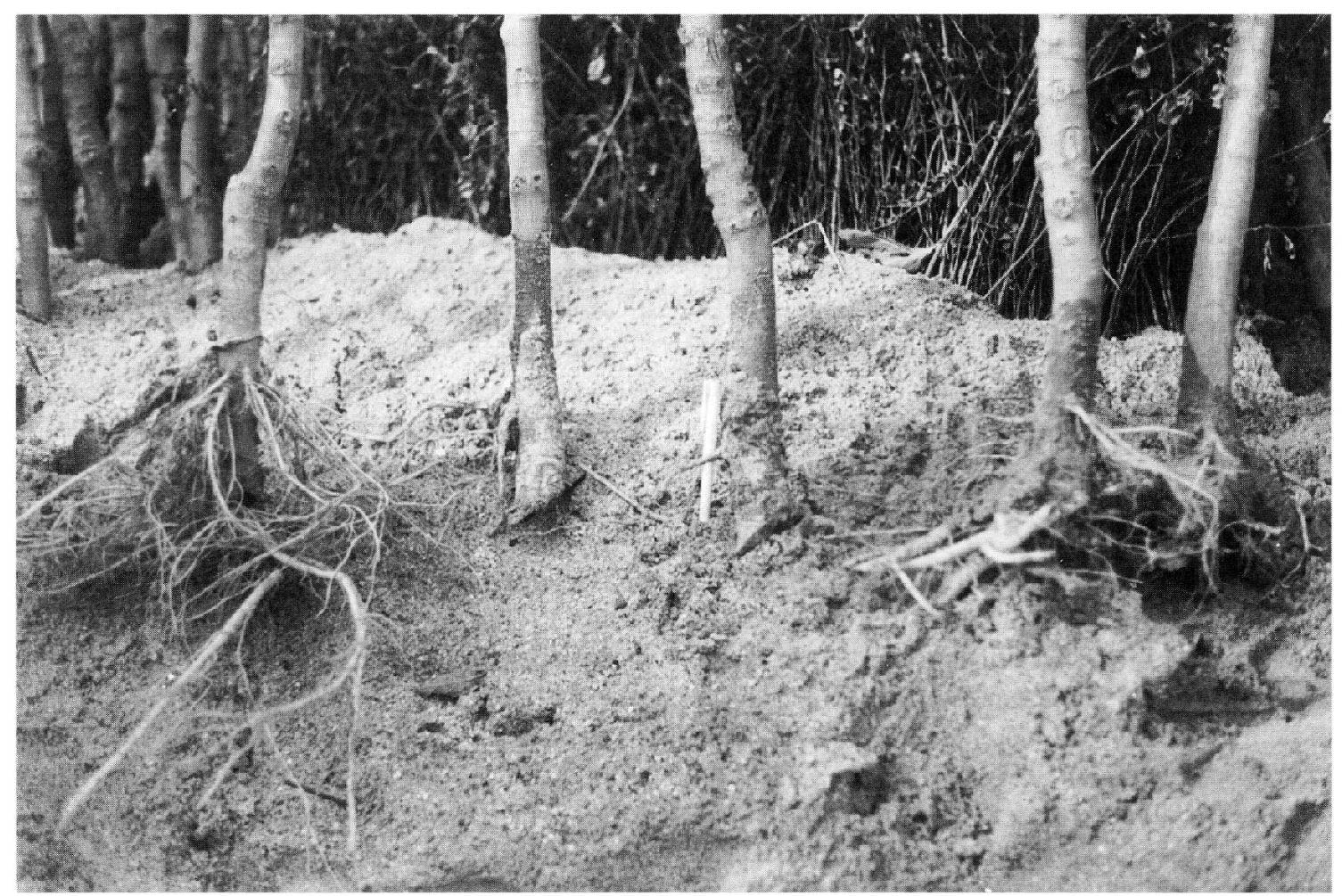

Foto 7.- Sistema radical de varios ejemplares arbóreos recibidos a raiz desnuda por el Contratista. A la izquierda se aprecia un sistema radical bueno. En el centro se ven dos raices completamente deficientes que obligaron al Equipo de Control y Vigilancia Ambiental a rechazar todos los ejemplares en estas condiciones. A la derecha se observan sistemas radicales intermedios, de los que se retiraron aquellos que presentaban caracteristicas menos satisfactorias.

- Plantas: procedencia, especie, dimensión, estado sanitario, presentación, enraizamiento, condiciones de almacenamiento, etc.

- Agua para riego e hidrosiembra.

- Estabilizantes, mulches, polímeros absorbentes.

- Mantas orgánicas, mallas, plásticas, y otros elementos estructurales.

- Etc. (Foto 7).

También es preciso supervisar la correcta ejecución de los trabajos previos a siembras, hidrosiembras y plantaciones:

- Espesor de tierra vegetal incorporada y su acabado superficial.

- Profundidad y acabado de operaciones de limpieza, desfonde, escarificado, etc.

- Preparación de los hoyos de plantación (dimensiones, ejecución, acabado).
- Acopio de suelos aceptables donde los materiales extraídos en la excavación del hoyo no resultan aprovechables.

- Colocación de mallas plásticas y otro tipo de medidas estructurales.

- Correcta conservación de tepes.

- Adecuado acopio y tratamiento de la tierra vegetal recuperada de la obra.

- Etc. (Fotos 8, a y b).

\section{5.- Control de los trabajos de revegetación}

En esta fase el Equipo de Control y Vigilancia supervisa los trabajos de revegetación propiamente dichos. Nuevamente, a título de ejemplo, se señalan seguidamente algunos de los principales cometidos a desarrollar:

a) En primer lugar, y con carácter general, se verifica que las condiciones ambientales sean apropiadas (viento, lluvia, tempero de la tierra, etc.). 
Fotos 8.- La extracción, mantenimiento y reposición de tepes son trabajos muy laboriosos (foto a) pero imprescindibles en zonas de alta montaña donde las condiciones topográficas y ambientales dificultan las labores de revegetación tradicionales. En la fotografía $b$ se aprecia un apilamiento de tepes en una zona de pastos de montaña donde se producen deslizamientos naturales del terreno (al fondo): en primer término se observa el talud de una carreter donde la vegetación no ha sido capaz de asentarse por si misma. durante años.

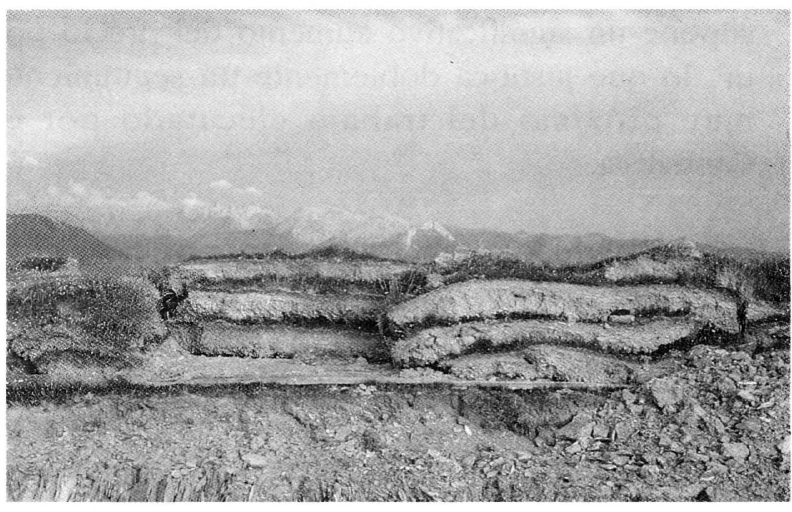

a

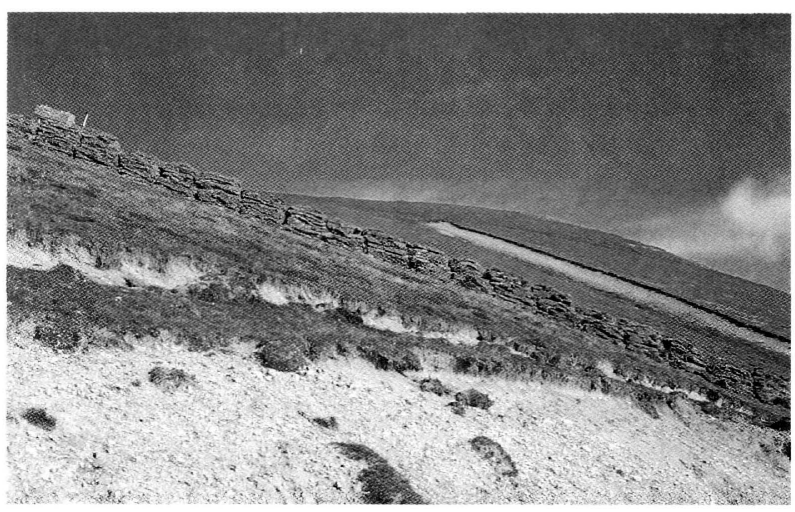

b) En la plantación se realiza un control visual de la ejecución, comprobando la correcta colocación de la planta en el hoyo, la incorporación en éste de todos los productos proyectados (abonos, estiércol, compuestos absorbentes, etc.), el riego de plantación, el retoque de los alcorques, etc. (foto 9).

c) En la hidrosiembra es esencial supervisar el correcto funcionamiento de la maquinaria, el llenado de la hidrosembradora con los productos indicados en el Pliego, la aplicación de las dosis adecuadas por $\mathrm{m}^{2} \mathrm{y}$ su reparto homogéneo, etc.

d) En la siembra hay que comprobar el eficaz funcionamiento de los mecanismos de distribución, la utilización de las especies proyectadas en la dosis prefijada, el aporte de abonos y todas aquellas peculiaridades que la obra exija.

e) En ocasiones, siembras e hidrosiembras irán acompañadas de la aplicación de elementos especiales de protección como son las mantas orgánicas o productos equivalentes, cuyo éxito reside en una cuidadosa ejecución. Este tipo de técnicas se aplica para solucionar problemas especiales y

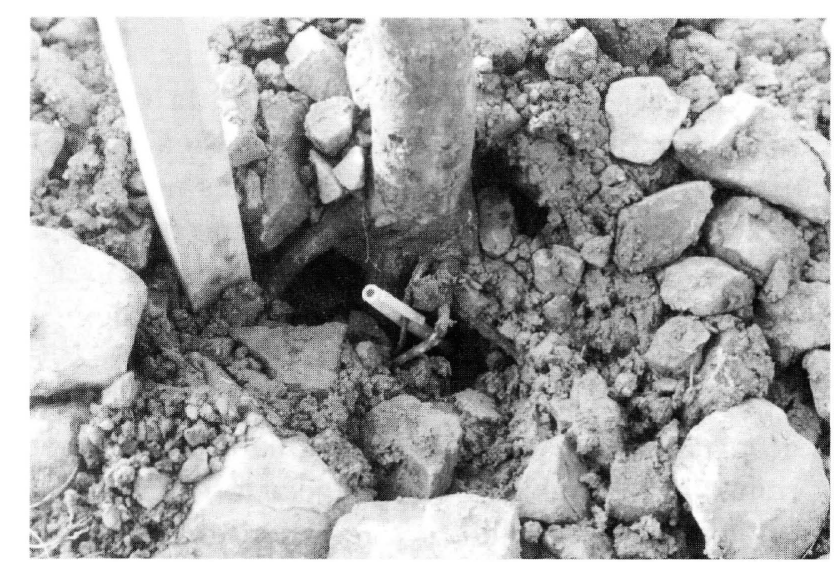

Foto 9.- Detalle de la plantación de un ejemplar arbóreo a raíz desnuda. El material de relleno, en lugar de estar constituido por "suelos aceptables" (tal y como establecía el Pliego y aconseja el sentido común) estaba formado casi exclusivamente por piedras, que no constituyen el sustrato adecuado y dejan tas raices al aire, provocando su muerte. El Equipo Ambiental obligó a replantar los ejemplares en estas condiciones, aportando tierra vegetal como material de relleno. 
supone un significativo aumento del precio por $\mathrm{m}^{2}$, lo que justifica doblemente un seguimiento muy próximo del trabajo ejecutado por el Contratista.

\subsection{Control de los trabajos de conservación y mantenimiento}

La revegetación no finaliza con la implantación del material vegetal, sino que conlleva la ejecución posterior de los trabajos de conservación y mantenimiento que el Pliego de Prescripciones Técnicas habrá definido oportunamente: riegos, abonados, retoque de alcorques, escardas, etc. en las cuantías, dosis y épocas prefijadas, y adaptados a la marcha de la obra.

Una tarea esencial de esta fase es el control y seguimiento de la evolución de la revegetación:

- Controles de germinación y nascencia en siembras e hidrosiembras.

- Control de marras en las plantaciones

Éstos deben conducir a fijar las zonas a resembrar y los árboles y arbustos a reponer. En este punto la labor del Equipo de Control y Vigilancia resulta esencial para conducir a sus justos términos el natural optimismo del Contratista al evaluar el resultado de su actuación y su tendencia a encontrar factores exteriores (daños por ganado,...) que justifiquen los fallos sufridos. El control de resiembras y reposiciones de marras se realiza con criterios similares a los indicados anteriormente.

\section{7. - Tareas generales}

Con carácter general y durante toda la obra el Equipo de Control y Vigilancia verifica que el Contratista adopte todas las precauciones necesarias para evitar que se produzca cualquier tipo de daño a la obra civil (contaminación del balasto con especies vegetales en ferrocarriles, roturas de conducciones enterradas en las excavaciones, etc.).

Por otro lado, un seguimiento detallado del avance y ritmo de los trabajos de revegetación permite ir proponiendo las modificaciones oportunas para la adecuada coordinación de todos los trabajos entre sí y con otros propios de la obra civil de que se trate.

Complementariamente se presta apoyo a la Dirección de Obra en la medición y abono de las obras, emitiendo periódicamente informes que recogen:

a) Relación valorada de la obra ejecutada al origen.

b) Medición total de la obra actualizada y valoración a los precios contractuales, desglosados en los correspondientes capítulos.

c) Medición y valoración desglosada de la obra pendiente.

d) Desviaciones de la obra actualizada respecto a la inicial.

\section{4.- COMPOSICIÓN DEL EQUIPO DE CONTROL Y VIGILANCIA Y EMISIÓN DE INFORMES}

La composición del Equipo de Control y Vigilancia y su grado de supervisión de los trabajos de corrección del impacto ambiental y de revegetación está en intima relación con la importancia y el volumen de las obras.

Cuando la inversión en obra civil se cifra en miles de millones de pesetas (autovías, autopistas, tren de alta velocidad, gasoductos, grandes canales de regadio, etc.), y consecuentemente el presupuesto destinado a la corrección de impactos ambientales es importante, se puede dar el nivel óptimo de seguimiento. Esto implica un control diario de los trabajos efectuados, realizando una ficha de ejecución por cada unidad de actuación, en la que se resume:

- Descripción de las tareas llevadas a cabo.

- Condiciones ambientales existentes en cada momento.

- Fecha de ejecución de cada tarea.

- Medición de los trabajos.

- Control periódico de los resultados obtenidos.

- Necesidad de repetición de los trabajos (aportes de tierra vegetal, resiembras, reposición de marras, ...).

- Trabajos de conservación, mantenimiento y reposición efectuados.

- Evolución del resultado final obtenido. 
- Cuantos datos complementarios e incidencias pueden ser relevantes.

Para desarrollar este trabajo es preciso disponer de un equipo a pie de obra compuesto por: Un titulado superior con experiencia en trabajos de corrección de impacto ambiental y revegetación, que actuará como jefe de Equipo y verá complementada su labor con otros técnicos, en número variable en función del volumen de trabajo.

Capataces con formación y experiencia en estos temas, en número adecuado a la entidad de las labores a desarrollar.

La composición numérica del equipo se verá incrementada en las épocas idóneas para la realización de los diferentes trabajos, mientras el resto del año podrá reducirse al tener que controlar solamente labores de conservación.

Frente a esta situación óptima, en otros casos la cuantía de las inversiones no permitirá mantener un equipo constantemente a pie de obra. En estas condiciones la labor del Equipo de Control y Vigilancia Ambiental puede concretarse a realizar visitas periódicas de supervisión de los trabajos y todas aquellas que por incidencias especiales pudieran resultar necesarias, emitiendo cada vez los informes correspondientes.

En ambos casos las funciones de control y vigilancia se plasmarán en informes periódicos a la Dirección de Obra (mensuales por ejemplo) que recogerán los datos de los trabajos que de forma sistemática se van supervisando y evaluando. De forma complementaria, se emitirán todos aquellos informes que sean necesarios como consecuencia de situaciones específicas, modificaciones, problemas especiales, falta de calidad de los materiales, fallos de ejecución, etc.

La supervisión debe extenderse a todo el plazo de garantía, aunque la intensidad del control sea menor y no parezca precisa la permanencia a pie de obra del equipo durante el mismo, resolviéndose las tareas con visitas e informes periódicos. A este respecto parece necesario sugerir la ampliación de los plazos de garantía a tres o cuatro años, incrementándose los presupuestos de ejecución en las cantidades oportunas para que no haya lugar a excusas de los contratistas para la no realización de las labores de conservación y mantenimiento. El sobrecoste puede considerarse mínimo y asegura de forma apreciable la inversión realizada. Es preciso elevar la calidad y la exigencia en la redacción y ejecución de los proyectos de corrección de impacto ambiental y revegetación, y en consonancia aumentar los presupuestos correspondientes, para que no puedan alegarse estrecheces económicas como justificante de obras incorrectamente ejecutadas. Con frecuencia lo barato acaba resultando caro. Así lo ha entendido ya alguna Administración Pública directamente relacionada con obras civiles de infraestructura, que junto a una mayor exigencia en la redacción de proyectos, ha acompañado una mejora apreciable en la remuneración de los mismos. Es de esperar que este planteamiento sea cada vez más general.

NOTA:

Con el fin de respetar el contenido íntegro de los artículos y debido a la extensión de la documentación recibida, INFORMES ha considerado oportuno en esta ocasión, dado el interés del tema tratado, publicar un número doble y así ofrecer una visión lo más completa posible del mismo.

Rogamos a nuestros suscriptores disculpen esta anomalía y las molestias que pueda ocasionarles. 